\title{
Imaging thrombus with radiolabelled monoclonal antibody to platelets
}

\author{
A M PETERS, J P LAVENDER, S G NEEDHAM, I LOUTFI, D SNOOK, A A EPENETOS, \\ $P$ LUMLEY, R J KEERY, N HOGG
}

\begin{abstract}
Indium-111-hydroxyquinoline labelled platelets, though useful in the detection of thrombus, have not gained widespread use owing to the time and technical skill required for their preparation. A study was therefore conducted evaluating a new method of imaging thrombus with platelets radiolabelled with a ${ }^{111}$ In labelled monoclonal antibody, P256, directed to the platelet surface glycoprotein complex IIb/IIIa. When the number of receptors occupied by P256 was less than $3 \%$ of the total available on the platelet surface platelet function, as assessed by platelet aggregometry, was undisturbed. P256 was radiolabelled with ${ }^{11}$ In using diethylenetriaminepenta-acetic acid, which achieved a specific activity of $185 \mathrm{MBq}(5 \mathrm{mCi}) / \mathrm{mg}$. No impairment of immunoreactivity was detected at this specific activity. Platelets were labelled with radiolabelled monoclonal antibody in vitro in two patients at a receptor occupancy of $6 \%$ and in vivo- that is, by direct intravenous injection of P256-in six patients at a receptor occupancy of $1 \%$. In vivo recovery and biodistribution kinetics suggested that after in vitro labelling platelets were minimally activated. The "'In kinetics recorded after intravenous P256 suggested rapid and efficient radiolabelling of platelets and gave no indication of platelet activation. Of the six patients who received intravenous $\mathbf{P 2 5 6}$, three had documented thrombus, two
\end{abstract}

\footnotetext{
Royal Postgraduate Medical School, Hammersmith Hospital, London W12 0HS

A M PETERS, MD, MRCPATH, senior lecturer, department of diagnostic radiology J P LAVENDER, FRCR, professor and consultant radiologist

S G NEEDHAM, MSC, research assistant, department of diagnostic radiology

I LOUTFI, MSC, MD, research fellow, department of diagnostic radiology

D SNOOK, BSC, research officer, department of clinical oncology

A A EPENETOS, PHD, MRCP, senior lecturer, department of clinical oncology

Glaxo Group Research Ltd, Ware, Herts

P LUMLEY, PHD, senior pharmacologist

R J KEERY, BSC, pharmacologist

Imperial Cancer Research Fund, London

N HOGG, PHD, staff scientist

Correspondence to: Dr Peters.
}

of whom gave positive results on P256 platelet scintigraphy. The third subject had chronic deep venous thrombosis and was scintigraphically negative.

Imaging thrombus using a radiolabelled monoclonal antibody directed to platelets appears to offer great potential as a simple, non-invasive approach to the diagnosis of thrombosis.

\section{Introduction}

Platelets labelled with indium-111, introduced in the late 1970s as a new method of imaging thrombus, ${ }^{12}$ have not gained widespread application, and conventional radiographic techniques such as contrast phlebography for deep venous thrombosis remain the favoured diagnostic approaches. The main drawback of "In labelled platelets is the time and technical skill required for cell separation and labelling, which has resulted in only a few regional centres making use of the technique for thrombus imaging.

In a search for new methods of cell labelling using cell specific agents which can label cells in whole blood or even in vivo we considered the potential of radiolabelled monoclonal antibodies directed to cell specific antigens. Oster et al have shown that this approach is feasible in dogs but it has not been applied to man. ${ }^{3}$ This paper describes our preliminary findings using a platelet specific monoclonal antibody with the aim of imaging thrombus in man. If this approach proves successful then this radiopharmaceutical will have the convenience of an "off the shelf" agent.

\section{Materials and methods}

Monoclonal antibody-P256 is an IgG1 mouse monoclonal antibody. It was derived from fusion of the P3-NS1/-1-Ag4-1 myeloma cell line with spleen cells from $\mathrm{BALB} / \mathrm{c}$ mice immunised with human peripheral blood mononuclear cells, as described. ${ }^{+}$The antibody reacts with the $130000 \mathrm{IIb}$ component of the platelet membrane glycoprotein complex IIb/IIIa, which is a heterodimer of $\mathrm{Mr} 130000$ and $115000 .^{5} \mathrm{P} 256$ is specific for the $\mathrm{Mr}$ $130000 \mathrm{IIb}$ component. It is thought to function in platelet-platelet aggregation $^{6}$ and to serve on platelets as a receptor for fibrinogen, which is instrumental in the participation of platelets in coagulation. ${ }^{78}$ Pure monoclonal antibody was isolated from ascitic fluid by protein A affinity chromatography. ${ }^{9}$ 
Effect of antibody on platelet function-The effect of P256 on platelet function at different levels of receptor occupancy was studied in vitro by measuring $(a)$ the rates of spontaneous aggregation in citrated plasma and $(b)$ the rates of aggregation in citrated platelet rich plasma induced by the proaggregants U46619 (a synthetic thromboxane mimetic; Upjohn), collagen, and adenosine diphosphate. Spontaneous aggregation was measured semiquantitatively under the microscope by counting and sizing platelet aggregates. Spontaneous and induced aggregation were quantified by electronic platelet counting ${ }^{10}$; only single platelets are counted, so that aggregation is recorded as a fall in platelet count.

Radiolabelling P256-P256 was labelled with "In using the bifunctional chelating agent diethylenetriaminepenta-acetic acid. ${ }^{11}$ One or two molecules of the chelating agent were complexed with each antibody molecule, giving a specific activity of $185 \mathrm{MBq}(5 \mathrm{mCi}) / \mathrm{mg}$ antibody. At this specific activity no impairment of antibody immunoreactivity could be detected using radioimmunoassay and enzyme linked immunosorbent assay.

In vitro platelet labelling-A normal volunteer and a patient with a suspected deep venous thrombosis who had been receiving heparin for 24 hours each donated venous blood (40 and $85 \mathrm{ml}$ respectively), acid citrate dextrose (National Institutes of Health, formula $\mathrm{A}$ ) being used as anticoagulant. The blood was centrifuged at $200 \mathrm{~g}$ for 10 minutes and the platelet rich plasma obtained. A platelet has been calculated as having 40000 receptors for P256. ${ }^{12}$ Thus $4.5 \mu \mathrm{g}$ radiolabelled antibody was added to $15 \mathrm{ml}$ of the volunteer's platelet rich plasma and $12 \mu \mathrm{g}$ to $42 \mathrm{ml}$ of the patient's platelet rich plasma, giving a maximum receptor occupancy of $6 \%$ in each case. After incubation for $\mathbf{4 5}$ minutes the labelled platelet rich plasma was returned to the subject, about $85 \%$ of the radioactivity being platelet associated. The injected doses were 0.3 and $2.6 \mathrm{MBq}(8.5$ and $70 \mu \mathrm{Ci})$ for the volunteer and patient respectively. For the patient dynamic gammacamera acquisition was performed for 30 minutes after injection.

In vivo platelet labelling-Six patients received $100 \mu \mathrm{g}$ radiolabelled antibody intravenously. The "II In dose ranged from $3 \cdot 7$ to $7 \cdot 4 \mathrm{MBq}$ (100 to $200 \mu \mathrm{Ci}$ ). In two subjects dynamic acquisition was performed for 30 minutes after injection. In one subject blood taken one hour after injection was centrifuged on a double density Percoll gradient and the percentage of radioactivity associated with the plasma and formed elements determined.

Platelet survival-Blood samples were taken periodically. Activity was measured in cell free plasma, platelet rich plasma, and whole blood. Platelet associated activity was then expressed as a function of time.

Imaging - Whole body images with regional views were obtained at 30 minutes, three hours, and 24 hours using a gammacamera (IGE $400 \mathrm{~A}$ or $400 \mathrm{~T}$ ) on line to a computer (MDS $\left.\mathrm{A}^{2}\right)$.

\section{Results}

\section{IN VITRO FUNCTION OF PLATELETS CARRYING P256}

Platelets carrying P256 on their surface underwent spontaneous aggregation to an extent that was proportional to the percentage of receptors assumed to be occupied (table I). At or below an occupancy of $3 \%$, however, no difference in spontaneous aggregation could be detected between platelets with P256 and control platelets. At receptor occupancies of greater than $10 \%$ the platelets underwent massive spontaneous aggregation. At a receptor occupancy of $6 \%$ aggregation in response to U46619 and collagen was increased in the platelet rich plasma from two of three normal donors but was normal or subnormal in response to adenosine diphosphate (table II).

\section{IN VIVO PLATELET KINETICS}

In vitro labelling-There was a progressive fall in platelet associated activity to $30 \%$ and $40 \%$ of the dose at 40 minutes and two hours after the re-

TABLE I-Spontaneous aggregation of platelets carrying P256 on their surface, assessed by microscopy and platelet counting

\begin{tabular}{|c|c|c|c|}
\hline \multirow{2}{*}{$\begin{array}{l}\text { Receptor } \\
\text { occupancy } \\
(\%)\end{array}$} & \multirow[b]{2}{*}{ Microscopy } & \multicolumn{2}{|c|}{$\%$ Fall in platelet count $/ 10 \mathrm{~min}$} \\
\hline & & Mean (range) & $\begin{array}{c}\text { No of } \\
\text { observations }\end{array}$ \\
\hline 0 & Occasional aggregates ( $2-3$ cells $)$ & $1 \cdot 3(0-1 \cdot 9)$ & 4 \\
\hline 2 & - & 0 & 1 \\
\hline 3 & Occasional aggregates $(2-3$ cells $)$ & - & \\
\hline 4 & Occasional clumps ( $5-7$ cells) & $0 \cdot 4(-1 \cdot 2-2 \cdot 0)$ & 2 \\
\hline 6 & Occasional clumps ( $8-10$ cells) & $4 \cdot 7(0-15 \cdot 0)$ & 5 \\
\hline $7-8 \cdot 5$ & - & $9 \cdot 0(4 \cdot 2-17 \cdot 0)$ & 4 \\
\hline 10 & Very few free cells & $74 \cdot 0$ & 1 \\
\hline
\end{tabular}

TABLE II-Aggregation in vitro of P256 platelets and control platelets in response to U46619, collagen, and adenosine diphosphate. (Values are doses of aggregant giving $50 \%$ reduction in platelet count)

\begin{tabular}{|c|c|c|c|c|c|c|c|}
\hline \multirow[b]{2}{*}{ Donor } & \multirow{2}{*}{$\begin{array}{c}\text { Receptor } \\
\text { occupancy } \\
(\%)\end{array}$} & \multicolumn{2}{|c|}{$\mathrm{U} 46619\left(10^{-7} \mathrm{~mol} / \mathrm{l}\right)$} & \multicolumn{2}{|c|}{ Collagen $(\mathrm{mg} / \mathrm{ml})$} & \multicolumn{2}{|c|}{$\begin{array}{c}\text { Adenosine } \\
\text { diphosphate } \\
10^{-7} \mathrm{~mol} / \mathrm{l}\end{array}$} \\
\hline & & Control & P256 & Control & $\mathrm{P} 256$ & Control & P256 \\
\hline 1 & $6 \cdot 4$ & 3.6 & 1.5 & 0.42 & 0.8 & 16 & 13 \\
\hline 2 & $7 \cdot 5$ & 5.6 & $3 \cdot 5$ & 1.4 & 0.58 & 29 & 47 \\
\hline 3 & 6.8 & 6.4 & 1.8 & 0.62 & $0 \cdot 16$ & 6.9 & 6.4 \\
\hline
\end{tabular}

injection of radiolabelled platelets in the patient and volunteer respectively. The subsequent time courses of platelet associated activity suggested an essentially normal platelet survival of about 160 hours in both subjects (fig 1). The time-activity curves recorded over the cardiac blood pool and spleen by dynamic imaging for 30 minutes after injection of radiolabelled platelets were very similar to those seen after injection of platelets labelled with ${ }^{111}$ In-hydroxyquinoline and reflect the equilibration of platelets between circulating blood and the splenic platelet pool. ${ }^{13}$ Liver activity, however, showed a slow, definite increase, consistent with some degree of platelet activation. ${ }^{14}$

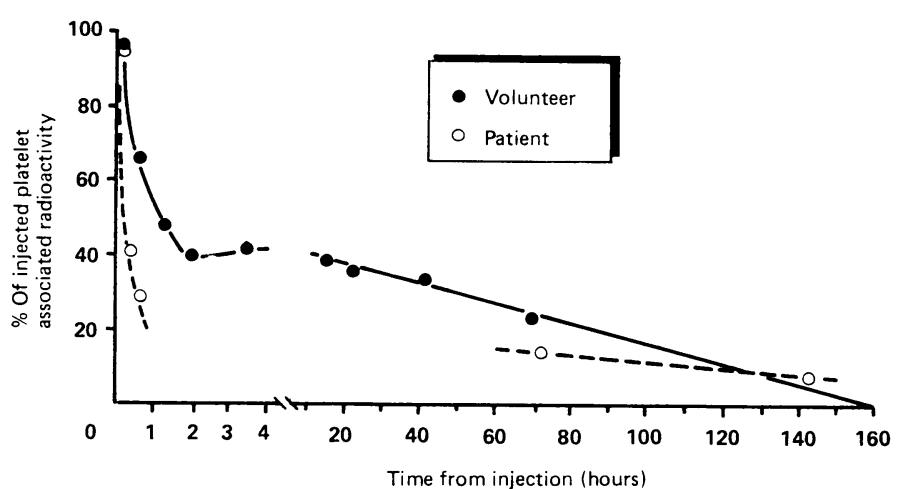

FIG 1-Time courses of platelet associated radioactivity after injection of platelets labelled in vitro with ${ }^{111}$ In-P256 in normal volunteer and in patient with suspected deep venous thrombosis.

In vivo labelling-After the administration of intravenous radiolabelled P256 which was calculated to give a maximum receptor occupancy of $1 \%$ no change in the peripheral blood platelet count could be detected up to five days after injection. One hour after injection roughly $80 \%$ of the radioactivity was cell associated, and $90-95 \%$ of this was platelet associated. The timeactivity curves recorded over the cardiac blood pool, liver, and spleen by dynamic imaging immediately after injection were identical with those seen after injection of platelets labelled with ${ }^{111}$ In-hydroxyquinoline or ${ }^{111}$ Intropolonate. ${ }^{1314}$ In particular, the liver curve remained low and flat, suggesting that the labelled platelets were in no way activated.

\section{IMAGING}

In vitro-The volunteer did not receive enough ${ }^{111}$ In for imaging. The patient had a whole body distribution of ${ }^{111} \mathrm{In}$ similar to that seen with platelets labelled in vitro with ${ }^{111}$ In-hydroxyquinoline-namely, high splenic activity, minimal hepatic activity, and a blood pool image. ${ }^{13}{ }^{14} \mathrm{He}$ had a positive contrast phlebogram but was negative for thrombus on labelled platelet imaging.

In vivo-Figure 2 shows the whole body distribution of radioactivity three hours after injection of radiolabelled P256. There was intense splenic activity, hepatic activity, and a blood pool image. This distribution was identical to that seen after injection of platelets labelled in vitro with ${ }^{11}$ Inhydroxyquinoline. Two patients had positive 24 hour images for thrombus (fig 2). One of these had deep venous thrombosis, shown by contrast phlebography, and the other was a patient receiving haemodialysis for chronic renal failure who had a thrombosed arteriovenous access shunt. One patient thought to have chronic deep venous thrombosis had a positive phlebogram and a negative platelet study. The remaining three patients in whom there was no other evidence for thrombus also gave negative results with P256. 


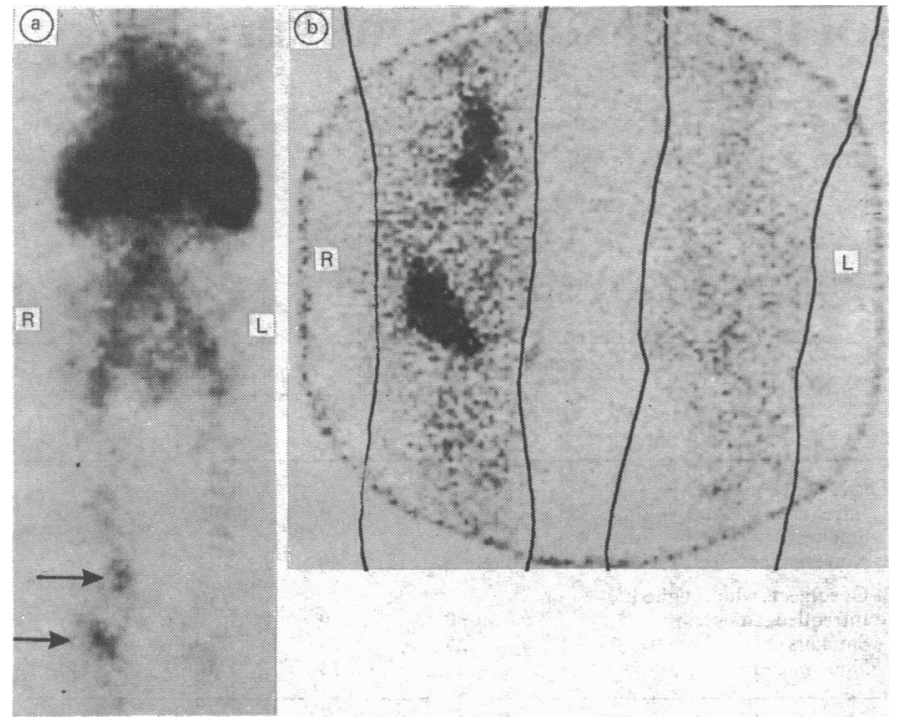

FIG 2-(a) Whole body image 24 hours after injection of ${ }^{111}$ In-P256 in patient with venous thrombus in right leg. In addition to blood pool, hepatic, and splenic activity, abnormal focal activity evident above and below right knee (arrows). (b) Local view of abnormal activity.

\section{Discussion}

Our first concern with this technique was its safety - firstly, with respect to the potential problems associated with murine monoclonal antibodies (especially the development of immunity or sensitivity, or both, to mouse protein) and, secondly, with respect to possible adverse effects of disturbed platelet function.

There is extensive experience in the use of radiolabelled monoclonal antibodies for imaging neoplastic lesions. ${ }^{15}$ This procedure has been found to be clinically safe and useful. Nevertheless, multiple injections of murine monoclonal antibodies into patients will be expected to stimulate an immune response. Several workers have examined this phenomenon, ${ }^{16}{ }^{17}$ and the general finding is that patients develop an antimouse globulin response after repeated administration. To reduce this, we can use antibody fragments Fab and $\left(\mathrm{Fab}^{1}\right)_{2}$ instead of whole immunoglobulin. ${ }^{18}$ Alternatively, with the use of recombinant DNA (deoxyribonucleic acid) technology it is now possible to replace the complementarity determining regions in a human antibody with those from a mouse in an attempt to "humanise" mouse monoclonal antibodies ${ }^{19}$ and eliminate or at least suppress a human antiglobulin response.

At a receptor occupancy of greater than $3 \%$ we found evidence of increased platelet aggregability, both spontaneous and in response to $\mathrm{U} 46619$ and collagen. If, however, we assume a rapid uniform dispersal of antibody after intravenous injection in a patient with a normal platelet count and a normal sized splenic platelet pool, $100 \mu \mathrm{g}$ will give a maximum receptor occupancy of $1 \%$, well below the level at which hyperaggregability was first noted in vitro. Furthermore, the use of antibody monovalent Fab fragments instead of whole immunoglobulin ${ }^{18}$ should reduce considerably the potential hazard of platelet hyperaggregability by eliminating the possibility of bivalent binding or Fc receptor cross linking.

In vitro labelling resulted in a whole body distribution of radioactivity that, apart from slightly higher liver activity, was very similar to that after in vivo labelling and after injection of platelets labelled by a conventional method. ${ }^{13} 14$ The time course of liver activity immediately after injection of platelets labelled in vitro with P256 and the relatively low recovery of platelet associated activity shortly after injection would be consistent with some degree of platelet activation. This might be expected on the basis of the platelet behaviour seen in vitro at a receptor occupancy of $5-6 \%$. The time courses of activity in spleen, liver, and peripheral blood after in vivo labelling suggest that platelets are labelled very efficiently and very rapidly in vivo and that their function remains undisturbed by the small amounts of antibody on their surface.
Apart from convenience, this highlights the advantage of in vivo over in vitro labelling. Furthermore, because of the greatly increased number of platelet receptors available with in vivo labelling more radiolabelled antibody can be injected, which, by virtue of the limitations imposed by the maximum attainable specific activity of labelled antibody (about $185 \mathrm{MBq}(5 \mathrm{mCi}) / \mathrm{mg}$ ), permits the administration of enough "In for optimal imaging.

The two patients with known recent thrombus had positive results with radiolabelled antibody. One case of old thrombus, which showed up on phlebography, gave negative results with P256, which may be a reflection of the functional nature of this novel form of imaging - that is, unless platelet adherence to the surface of the thrombus is ongoing at the time of P256 injection the study will give a negative result. The possibility of imaging pulmonary embolism simultaneously is exciting.

Other potential indications for the technique are renal allograft rejection,,$^{20}$ platelet uptake on to prosthetic arterial surfaces, ${ }^{21}$ and, possibly of greater interest, arterial and intracardiac thrombus. ${ }^{22} 23$ Furthermore, the apparent ease with which radiolabelled P256 labels platelets in vivo should encourage the search for further cell specific monoclonal antibodies with the ability to label efficiently other circulating blood cells in vivo for diagnostic imaging.

In conclusion, we report the development of an agent, ${ }^{11}$ In labelled monoclonal antibody, for the non-invasive imaging of thrombus. This could be made available on a wide scale as a relatively simple test, not requiring the time consuming preliminary laboratory work previously associated with ${ }^{11}$ In cell labelling.

AMP is supported by the Wellcome Trust, and SGN was supported by the Nuffield Foundation. ${ }^{11}$ In was kindly supplied by Amersham International. We are grateful to Belinda Henderson and Penny George for help with radiography and to Joanna Ashburner for secretarial work.

\section{References}

1 McAfee JG, Thakur ML. Survey of radioactive agents for in-vitro labelling of phagocytic leucocytes. I. Soluble agents. I Nucl Med 1976;17:480-7.

2 Knight LC, Primeau JL, Siegel BA, Welch MJ. Comparison of In-111-labelled platelets and iodinated fibrinogen for the detection of deep vein thrombosis. F Nucl Med 1978;19:891-4.

3 Oster ZM, Srivastava SC, Som P, et al. Thrombus radioimmuno-scintigraphy: an approach using monoclonal antiplatelet antibody. Proc Natl Acad Sci USA 1985;82:3465-8.

4 Bai Y, Durbin H, Hogg N. Monoclonal antibodies specific for platelet glycoproteins react with human monocytes. Blood 1984;64:139-46.

5 Phillips DR, Agin PP. Platelet defects in Glanzmann's thrombasthenia: evidence for decreased mount of two major glycoproteins. I Clin Invest 1977;60:535-45.

6 Phillips DR, Jenning LK, Edwards HH. Identification of membrane proteins mediating the interaction of human platelets. $\mathcal{F}$ Cell Biol 1980;86:77-86.

7 Nachman RL, Leung LLK. Complex formation of platelet membrane proteins IIb and IIIa with fibrinogen. $\mathcal{F}$ Clin Invest 1982;69:263-9.

8 Gostad GD, Brosstad F, Krutnes MB, Hagen I, Solum NO. Fibrinogen-binding properties of the human platelet glycoprotein IIb-IIIa complex. A study using crossed-radioimmunoelectrophoresis. Blood 1982;60:663-71.

9 Ey DL, Prowse SJ, Jenkin CR. Isolation of pure IgGl, IgG2a, IgG2b immunoglobulins from mouse serum using protein A-sepharose. Immunochemistry 1978;15:429-36.

10 Lumley P, Humphrey PPA. A method for quantitating aggregation and analysing drug receptor interactions on platelets in whole blood in vitro. $f$ Pharmacol Methods 1981;6:153-66.

11 Hnatowich D, Lague WWW, Childs RL, et al. Radioactive labelling of antibody: a single and efficient method. Science 1983;220:613-5.

12 McEver RP, Baenziger NL, Majerus PW. Isolation and quantitation of the platelet membrane glycoprotein deficient in thrombasthenia using a monoclonal hybridoma antibody. $\mathcal{F}$ Clin Invest 1980;66:1311-8.

13 Peters AM, Lane IF, Sinclair M, Irwin JTC, McCollum CN. The effects of thromboxane antagonism on the transit time of platelets through the spleen. Thromb Haemost 1985;54:495-7.

14 Peters AM, Saverymuttu SH, Malik F, Ind PW, Lavender JP. Intrahepatic kinetics of indium111-labelled platelets. Thromb Haemost 1985;54:595-8.

15 Dick HM. Regular review: monoclonal antibodies in clinical medicine. $\mathrm{Br} \mathrm{Med} \mathcal{f} 1985 ; 291: 762-4$.

16 Schroff RW, Foon KA, Beatty SM, et al. Human antimurine immunoglobulin responses in patients receiving monoclonal antibody therapy. Cancer Res 1985;45:879-85.

17 Courtenay-Luck N, Epenetos AA, Dhouin B, et al. Development of primary and secondary immune responses to mouse monoclonal antibodies used in the diagnosis and therapy of malignant disease. Cancer Res (in press).

18 Wahl RL, Racker C, Philpott GW. Improved radioimaging and tumor localisation with monoclonal $\left(\mathrm{Fab}^{1}\right)_{2}$. F Nucl Med 1983;24:316-25.

19 Morrison SL, Johnson MJ, Herzenberg LA, Oi VT. Chimeric human antibody molecules: mouse antigen binding domain with human constant region domains. Proc Natl Acad Sci USA 1984;81:6-4.

20 Fenech A, Nicholls A, Smith FW. Indium labelled platelets in the diagnosis of renal transplan rejection: preliminary findings. Br $\mathcal{F}$ Radiol $1981 ; 54: 325-7$.

21 Goldman M, Norcott HC, Hawker RJ, Hail C, Drolc Z, McCollum CN. Femoro-popliteal bypass grafts-an isotope technique allowing in-vivo comparison of thrombogenicity. $\mathrm{Br} \mathcal{F}$ Sur 1982;69:380-2.

22 Davis HH, Siegel BA, Sherman LA, et al. Scintigraphic detection of carotid atherosclerosis with indium-111 labelled autologous platelets. Circulation 1980;61:982-8.

23 Ezekowitz MD, Wilson DA, Smith EO, et al. Comparison of indium-111 platelet scintigraphy and two dimensional echocardiography in the diagnosis of left ventricular thrombi. $N$ Engl f Med 1982;306:1509-13.

(Accepted 16 September 1986)

, 